\title{
Características agronômicas do trigo em função de Azospirillum brasilense, ácidos húmicos e nitrogênio em casa de vegetação
}

\author{
Luan F. O. S. Rodrigues ${ }^{1}$, Vandeir F. Guimarães ${ }^{2}$, Mônica B. da Silva ${ }^{3}$, \\ Artur S. Pinto Junior ${ }^{4}$, Jeferson Klein ${ }^{5} \&$ Andreia C. P. R. da Costa ${ }^{6}$ \\ ${ }^{1}$ PPGA/FCA/UNESP, Botucatu, SP. E-mail: luanf_rodrigues@hotmail.com (Autor correspondente) \\ ${ }^{2}$ PPGA/UNIOESTE, Marechal Cândido Rondon, PR. E-mail: vandeirfg@yahoo.com.br \\ ${ }^{3}$ PPGA/FCA/UNESP, Botucatu, SP. E-mail: monica.bartira@hotmail.com \\ ${ }^{4}$ PPGA/UNIOESTE, Marechal Cândido Rondon, PR. E-mail: artur_bio@hotmail.com \\ ${ }^{5}$ PPGA/UNIOESTE, Marechal Cândido Rondon, PR. E-mail: jefersonklein@yahoo.com.br \\ ${ }^{6}$ PPGA/UNIOESTE, Marechal Cândido Rondon, PR. E-mail: andreiacpr@hotmail.com
}

Palavras-chave:

Triticum aestivum $\mathrm{L}$. Azospirillum brasilense substâncias húmicas

\section{R E S U M O}

Objetivou-se, neste estudo, verificar o efeito do uso combinado de Azospirillum brasilense, ácidos húmicos e diferentes doses de nitrogênio nas características agronômicas do trigo. Os experimentos foram instalados no dia 21 de maio de 2011 e a colheita foi procedida no dia 13 de setembro de 2011 . O delineamento experimental adotado foi o de blocos casualizados em esquema fatorial $4 \times 4$, com quatro repetições. O primeiro fator se refere à combinação da estirpe $\mathrm{Ab}-\mathrm{V}_{5}$ de A. brasilense com os ácidos húmicos, sendo utilizados os seguintes tratamentos: controle; $\mathrm{Ab}-\mathrm{V}_{5}$; ácido húmico e $\mathrm{Ab}-\mathrm{V}_{5}$ +ácido húmico e o segundo fator se refere às doses de nitrogênio $(0,30,60$ e $90 \mathrm{~kg} \mathrm{ha}^{-1} \mathrm{~N}$ ). A maioria das variáveis em análise apresentou efeito linear positivo dos tratamentos em função da adubação nitrogenada sendo que apenas para a variável massa de cem grãos este efeito foi linear negativo. Não houve diferença significativa entre as variâncias, na produção de grãos. Pôde-se concluir que o uso combinado de $\mathrm{Ab}-\mathrm{V}_{5}+$ ácido húmico promove principalmente a produção de matéria seca de folhas e não é responsivo à adubação nitrogenada para os demais componentes produtivos em estudo nem para a produtividade dos grãos.
Key words:

Triticum aestivum $\mathrm{L}$. Azospirillum brasilense humic substances

\section{Agronomic characteristics of wheat due to Azospirillum brasilense, humic acids and nitrogen in greenhouse}

\begin{abstract}
A B S T R A C T
The objective of this study was to investigate the effect of the combined use of Azospirillum brasilense, humic acid and different levels of nitrogen on agronomic characteristics of wheat under greenhouse conditions. The experiments were installed on May 21, 2011 and proceeded to harvest on September 13,2011. The experimental design was a randomized complete block in a $4 \times 4$ factorial design with four replications. The first factor relates to the combination of strain $\mathrm{Ab}-\mathrm{V}_{5}$ of $\mathrm{A}$. brasilense with humic acids, with the following treatments: control, $\mathrm{Ab}-\mathrm{V}_{5}$, humic acid and $\mathrm{Ab}-\mathrm{V}_{5}+$ humic acid and the second factor refers to nitrogen levels $\left(0,30,60\right.$ and $\left.90 \mathrm{~kg} \mathrm{ha}^{-1} \mathrm{~N}\right)$. Most variables in the analysis had a positive linear effect of treatments depending on nitrogen fertilization, and only for variable weight of hundred grains, the negative effect was linear. There were no significant differences between the variances in grain production. It was concluded that the combined use of $\mathrm{Ab}-\mathrm{V}_{5}+$ humic acid promotes the production mainly of dry leaves and are not responsive to nitrogen fertilizer for other productive components under study, as well as grain yield.
\end{abstract}

\section{INTRODUÇÃO}

A cultura do trigo (Triticum aestivum L.) é de grande importância no agronegócio do Brasil, sendo também de grande destaque na economia da região Oeste do Paraná. Esta cadeia produtiva abrange setores como a pesquisa, a produção, a industrialização e a comercialização, gerando milhares de empregos no país.

O trigo é o segundo cereal mais cultivado mundialmente (MAPA, 2011). No Brasil, a previsão de cultivo de trigo em 2012/13 é de aproximadamente 2,1 milhões de hectares e uma produção de aproximadamente 6,0 milhões de toneladas de grãos. A estimativa de cultivo para o Estado do Paraná é de uma área de 871,5 mil hectares, com produção de 2,1 milhões de toneladas de trigo (CONAB, 2012).

Dentre os insumos utilizados a adubação nitrogenada representa grande parte dos custos produtivos e sua aplicação em gramíneas, como o trigo, eleva significativamente o custo de produção. Porém é indispensável, devido ao nitrogênio, se constituir o macro elemento mais limitante na produtividade do trigo visto que determina o número de afilhos ou perfilhos, 
sendo essencial na fase de formação dos nós e no início do alongamento do colmo (Sala et al., 2005).

Assim e em razão da crescente busca por sustentabilidade nos sistemas agrícolas de produção, alguns autores têm apresentado, como forma alternativa para a economia de fertilizante nitrogenado, a fixação biológica de nitrogênio (FBN) a qual pode suplementar ou, até mesmo, substituir a utilização desses fertilizantes (Baldani \& Baldani, 2005; Bergamaschi et al., 2007; Hungria et al., 2010).

Uma das possibilidades para viabilizar uma produção com menores custos sem prejudicar o ambiente seria a utilização do melhoramento genético das plantas. Por outro lado, a utilização dos recursos biológicos do solo deve ser considerada como a de bactérias promotoras do crescimento vegetal, que fixam nitrogênio $\left(\mathrm{N}_{2}\right)$ para a planta e produzem hormônios de crescimento, como auxinas e giberelinas, estimulando o desenvolvimento do vegetal (Dobbelaere \& Croonenborghs, 2002). Existe, porém, uma relação bastante específica entre a estirpe da bactéria utilizada com a cultivar do vegetal que se deseja produzir; a este evento se denomina especificidade planta-bactéria e, para Cantarella (2007) é uma das principais causas de inconsistência de ganhos produtivos com a utilização de bactérias promotoras do crescimento vegetal. A utilização de matéria orgânica estabilizada talvez possa minimizar o efeito da especificidade do trigo.

A matéria orgânica presente no solo é oriunda da mistura de diversos produtos de vários processos de decomposição resultantes da degradação química e biológica de resíduos vegetais e da atividade microbiana (Canellas et al., 2002). E as substâncias húmicas ( $\mathrm{SHs}$ ) constituem o produto final de decomposição de resíduos orgânicos e representam o principal componente da matéria orgânica em água, solos e sedimentos (Canellas et al., 2006).

Os ácidos húmicos são utilizados no meio agrícola como condicionador do solo haja vista que favorecem a estabilidade iônica da solução do solo e podem proporcionar, ao vegetal, aumento no tamanho e no número de raízes, incrementos na absorção de nutrientes e nas taxas de crescimento (Arancon et al., 2006; Cunha et al., 2009; Pinheiro et al., 2010).

Os ácidos húmicos podem atuar no aumento de bactérias diazotróficas introduzidas no interior da planta e, consequentemente, no incremento dos efeitos benéficos sobre a planta hospedeira (Marques Júnior et al., 2008; Conceição et al., 2008; 2009). Isto pode ser hipoteticamente explicado como parte dos efeitos que os ácidos húmicos promovem sobre o crescimento vegetal, pelo maior enraizamento e aumento no número de sítios de mitose e emergência de raízes laterais, elevando também o número de pontos de infecção para as bactérias (Conceição et al., 2008; 2009).

Assim, este trabalho apresenta, como hipóteses, que a inoculação com bactérias promotoras do crescimento vegetal combinada com a pulverização foliar de matéria orgânica estabilizada, pode favorecer os componentes produtivos e a produtividade do trigo além de reduzir a quantidade total de nitrogênio requerida pela cultura quando aplicada em uma cultivar de trigo responsiva à adubação nitrogenada.

O objetivo deste estudo foi verificar, em relação aos componentes produtivos e à produção de grãos de trigo, o efeito do uso combinado de bactérias promotoras do crescimento vegetal, matéria orgânica estabilizada e diferentes doses de nitrogênio.

\section{Material e Métodos}

Os experimentos foram instalados no dia 21 de maio de 2011 e a colheita foi procedida no dia 13 de setembro de 2011. Dois experimentos foram conduzidos em condições de cultivo protegido, na Estação de Horticultura e Cultivo Protegido "Prof. Dr. Mário César Lopes”, pertencente ao Núcleo de Estações Experimentais da Universidade Estadual do Oeste do Paraná - Campus de Marechal Cândido Rondon (PR). A estação está localizada entre as coordenadas geográficas $24^{\circ} 33^{\prime} 29,48^{\prime \prime} \mathrm{S}$ e $54^{\circ} 02^{\prime} 44,13^{\prime \prime} \mathrm{W}$, com altitude média de $410 \mathrm{~m}$.

A região é classificada climaticamente por Köppen como Cfa - Clima subtropical, com temperatura média no mês mais frio inferior a $18^{\circ} \mathrm{C}$ (mesotérmico) e temperatura média no mês mais quente acima de $22^{\circ} \mathrm{C}$, com verões quentes, geadas pouco frequentes e tendência de concentração das chuvas nos meses de verão; contudo, sem estação seca definida.

O delineamento experimental adotado foi o de blocos casualizados em esquema fatorial 4 x 4, com quatro repetições, totalizando 64 unidades experimentais. $\mathrm{O}$ primeiro fator se refere à combinação de bactérias promotoras do crescimento vegetal e matéria orgânica estabilizada sendo utilizados os seguintes tratamentos: controle; estirpe $\mathrm{Ab}-\mathrm{V}_{5}$ de Azospirillum brasilense; ácido húmico $(\mathrm{AH})$ e $\mathrm{Ab}-\mathrm{V}_{5}+\mathrm{AH}$; o segundo fator se refere às doses de nitrogênio $\left(0,30,60\right.$ e $\left.90 \mathrm{~kg} \mathrm{ha}^{-1}\right)$.

Como unidade experimental foram utilizados vasos de polietileno número 5 , com capacidade para $15,0 \mathrm{dm}^{3}$, os quais foram preenchidos com aproximadamente $13,5 \mathrm{dm}^{3}$ de solo peneirado em malha de $5,0 \mathrm{~mm}$. O solo utilizado nos experimentos é classificado como Latossolo Vermelho Eutroférrico (LVef) (EMBRAPA, 2006), de textura muito argilosa, retirado da camada de 0 a $20 \mathrm{~cm}$ coletado no próprio município. $\mathrm{O}$ solo apresentou as seguintes características químicas e físicas: $\mathrm{P}=32,01 \mathrm{mg} \mathrm{dm}^{-3} ; \mathrm{MO}=12,30 \mathrm{~g} \mathrm{dm}^{-3}$; $\mathrm{pH}\left(\mathrm{CaCl}_{2}\right.$ a $\left.0,01 \mathrm{~mol} \mathrm{~L}^{-1}\right)=4,80 ; \mathrm{H}+\mathrm{Al} ; \mathrm{Al} ; \mathrm{K} ; \mathrm{Ca}$ e; $\mathrm{Mg}$ $=3,87 ; 0,20 ; 0,58 ; 2,45$ e $0,95 \mathrm{cmol}_{\mathrm{c}} \mathrm{dm}^{-3}$, respectivamente; $\mathrm{Cu} ; \mathrm{Zn} ; \mathrm{Mn}$ e; $\mathrm{Fe}=4,10 ; 3,00 ; 45,00$ e $59,10 \mathrm{mg} \mathrm{dm}^{-3}$, respectivamente; argila; silte e; areia $=721,0 ; 108,0$ e; 171,0 $\mathrm{g} \mathrm{kg}^{-1}$, respectivamente.

Depois de peneirado o solo foi batido em betoneira juntamente com os adubos, no intuito de uma distribuição mais homogênea seguindo a recomendação de adubação proposta por Marchioro \& Franco (2010). Foram utilizados, neste momento, superfosfato simples para fornecimento de fósforo e cloreto de potássio para o fornecimento de potássio, a adubação nitrogenada foi parcelada e aplicados $30 \mathrm{~kg} \mathrm{ha}^{-1}$ 
por ocasião da semeadura e o restante no início do estádio de perfilhamento das plântulas (15 $\mathrm{DAE}$ ), respeitando-se os limites da quantidade de $\mathrm{N}$ de cada tratamento, adotando-se a ureia para o fornecimento desse nutriente.

Adotou-se, como material vegetal para este trabalho, a cultivar de trigo CD 150, obtida pela COODETEC - Cooperativa Central Agropecuária de Desenvolvimento Tecnológico e Econômico Ltda., lançada no ano de 2009. Este material é moderadamente resistente ao acamamento, os grãos apresentam qualidade industrial como trigo melhorador e a cultivar é exigente quanto à fertilidade do solo.

Antes da semeadura procedeu-se à inoculação das sementes com a estirpe $\mathrm{Ab}-\mathrm{V}_{5}$ de $A$. brasilense. Obteve-se o inoculante pelo Núcleo de Fixação Biológica de Nitrogênio do Departamento de Bioquímica e Biologia Molecular da Universidade Federal do Paraná (UFPR), campus de Curitiba, PR, que continha cerca de $2 \times 10^{8}$ UFC $\mathrm{mL}^{-1}$, dos quais se aplicou a proporção de 2,0 $\mathrm{mL}$ para cada 1000 sementes e em seguida deixou-se à sombra, durante quatro horas. Seis sementes foram semeadas por vaso e no momento da aplicação foliar de nitrogênio procedeu-se ao desbaste conduzindo-se duas plantas por vaso.

O ácido húmico foi obtido da purificação de vermicomposto, pelo Laboratório de Biotecnologia da Universidade Federal do Norte Fluminense - UENF, estabelecido em Campos dos Goytacazes, RJ. O material foi previamente dissolvido em água, na proporção de $13,5 \mathrm{mg} \mathrm{L}^{-1}$, sendo pulverizados, nas plantas, 20 $\mathrm{mL}$ por vaso desta solução, no início do estádio de alongamento de colmo pela escala Zadocks, aos 27 DAE.

O primeiro experimento foi conduzido até o início do estádio de emborrachamento, aos $52 \mathrm{DAE}$, de onde foram obtidos os dados de matéria seca de folhas (MSF) e de colmo mais bainhas (MSC + B). Visando à determinação dessas variáveis, as plantas foram colhidas e suas estruturas previamente separadas e acondicionadas em sacos de papel tipo Kraft; em seguida, levadas à estufa de circulação forçada de ar, mantida na temperatura de $65 \pm 3^{\circ} \mathrm{C}$, por aproximadamente $96 \mathrm{~h}$; as pesagens foram realizadas em balança digital analítica, modelo FA $2104 \mathrm{~N}$, da Celtac, com precisão de 0,0001 g; já o segundo experimento foi conduzido até a maturação fisiológica do trigo, aos 106 DAE (o ciclo da cultivar foi reduzido em aproximadamente sete dias em razão do experimento ter sido realizado em casa de vegetação). Deste experimento foram avaliadas as características produtivas: número de espigas por planta (NE), comprimento médio de espigas (CE) mensuradas com auxílio de um paquímetro digital graduado em $\mathrm{mm}$, número de espiguetas por planta (NEP), número de grãos por planta (NGP), massa de cem grãos (M100) e produtividade (PROD) em que, para obtenção dos valores de M100 e PROD, os grãos foram levados à estufa de circulação forçada de ar e mantidos na temperatura de $103 \pm 3{ }^{\circ} \mathrm{C}$, pelo período de $24 \mathrm{~h}$ após tabulados, os dados de MSC + B e NGP foram transformados em $\sqrt{\mathrm{x}+0,5}$ para atingir a normalidade pelo teste de Lilliefors e, em seguida, todas as variáveis foram submetidas à ANOVA, pelo teste F de Fisher-Snedecor; depois deste procedimento realizaram-se as análises de regressão; para ambas as análises utilizou-se o aplicativo computacional SISVAR - Sistema de Análise de Variância, v. 5.3.

\section{Resultados e Discussão}

Das variáveis analisadas todas apresentaram interação significativa entre os fatores de uso combinado de $\mathrm{Ab}-\mathrm{V}_{5}$ com $\mathrm{AH}$, associados à adubação nitrogenada, com exceção apenas de PROD, na qual não foram verificadas variâncias significativamente diferentes para nenhuma das fontes de variação analisadas (Tabela 1).

Com relação à matéria seca de folha (Figura 1A) observase que apenas o tratamento controle foi responsivo à adubação nitrogenada sendo que, com a dose de $90 \mathrm{~kg} \mathrm{ha}^{-1} \mathrm{~N}$ foram produzidos, em média, 2,44 g. Para os demais tratamentos não houve respostas à fertilização nitrogenada porém se ressalta que a adição de ácido húmico, a inoculação de bactérias e o uso conjunto de $\mathrm{Ab}-\mathrm{V}_{5}+\mathrm{AH}$, aumentaram o desenvolvimento da parte aérea em relação ao controle promovendo acúmulo de matéria seca das folhas.

Para os valores de matéria seca de colmo mais bainha (Figura 1B), observa-se que, com a dose de $90 \mathrm{~kg} \mathrm{ha}^{-1}$ de $\mathrm{N}$, os tratamentos apresentaram maiores valores com exceção do controle em que não houve variações significativas em função da dose de nitrogênio utilizada; apesar disto, o tratamento com

Tabela 1. Resumo das análises de variâncias para matéria seca de folhas (MSF), matéria seca de colmo e bainhas (MSC + B), número de espigas por planta (NE), comprimento médio de espigas (CE), número de espiguetas por planta (NEP), número de grãos por planta (NGP), massa de cem grãos (M100) e produção por planta (PROD), de trigo, cultivar CD 150, submetido ao uso combinado de ácido húmico ( $\mathrm{AH}$ ) e estirpe $A b-\mathrm{V}_{5}$ de Azospirillum brasilense, em função de doses de nitrogênio

\begin{tabular}{|c|c|c|c|c|c|c|c|c|c|}
\hline \multirow{2}{*}{ FV } & \multirow{2}{*}{ GL } & \multicolumn{8}{|c|}{ Quadrados Médios } \\
\hline & & MSF & MSC+B & NE & CE & NEP & NGP & M100 & PROD \\
\hline$A b-V_{5} / A H$ & 3 & $18,74^{\star \star}$ & $0,20^{\text {ns }}$ & $1,56^{\mathrm{ns}}$ & $46,41^{\text {ns }}$ & $159,91^{\mathrm{ns}}$ & $0,36^{\text {ns }}$ & $0,22^{\text {ns }}$ & $0,11^{\text {ns }}$ \\
\hline Doses N & 3 & $1,23^{\circ}$ & $2,63^{* *}$ & $45,62^{* *}$ & $238,82^{\star *}$ & $3783,61^{* *}$ & $21,01^{\star *}$ & $8,23^{\star *}$ & $0,12^{\text {ns }}$ \\
\hline Interação & 9 & $1,10^{*}$ & $0,30^{\circ}$ & $4,57^{\circ}$ & $63,19^{*}$ & $405,15^{0}$ & $5,54^{\circ}$ & $0,73^{\circ}$ & $0,84^{\text {ns }}$ \\
\hline Resíduo & 45 & 0,50 & 0,16 & 2,56 & 28,85 & 224,38 & 2,98 & 0,38 & 0,53 \\
\hline CV (\%) & - & 25,46 & 16,26 & 22,61 & 7,18 & 25,71 & 17,10 & 20,34 & 24,76 \\
\hline Média & - & 2,78 & 2,42 & 7,08 & 74,85 & 58,27 & 10,10 & 3,05 & 2,94 \\
\hline
\end{tabular}

${ }^{n s}$ Não significativo, ${ }^{0},{ }^{*} \mathrm{e}^{\star \star}$ Significativo a 0,10, 0,05 e 0,01 de probabilidade respectivamente, pelo teste de Fisher-Snedecor 
a combinação de $\mathrm{Ab}-\mathrm{V}_{5}+$ ácido húmico foi o que apresentou o maior valor de matéria seca na maior dose de $\mathrm{N}$, de 3,0 g.

Neste sentido, Sala et al. (2007b) verificaram que a produção de matéria seca pela parte aérea de plantas de trigo duplicou nos tratamentos que receberam a inoculação com bactérias diazotróficas, em relação à testemunha; entretanto, este resultado mais expressivo só foi obtido pelos tratamentos nos quais se aplicou baixa quantidade de $P$.

Considerando-se que o solo utilizado para a condução do presente experimento apresentava um elevado índice de $\mathrm{P}$ (teores de $\mathrm{P}>9,0 \mathrm{mg} \mathrm{dm}^{-3}$ ) isto pode ter contribuído para que os valores de MSF e MSC $+\mathrm{B}$ do trigo inoculado com $\mathrm{Ab}-\mathrm{V}_{5}$, sem $\mathrm{AH}$, não diferissem do tratamento controle.

$\mathrm{O} \mathrm{AH}$, aumentando o acúmulo de matéria seca, também foi observado por Baldotto et al. (2009) trabalhando com a produção de mudas de abacaxi "in vitro" em função da pulverização foliar de $\mathrm{AH}$, quando obtiveram incrementos
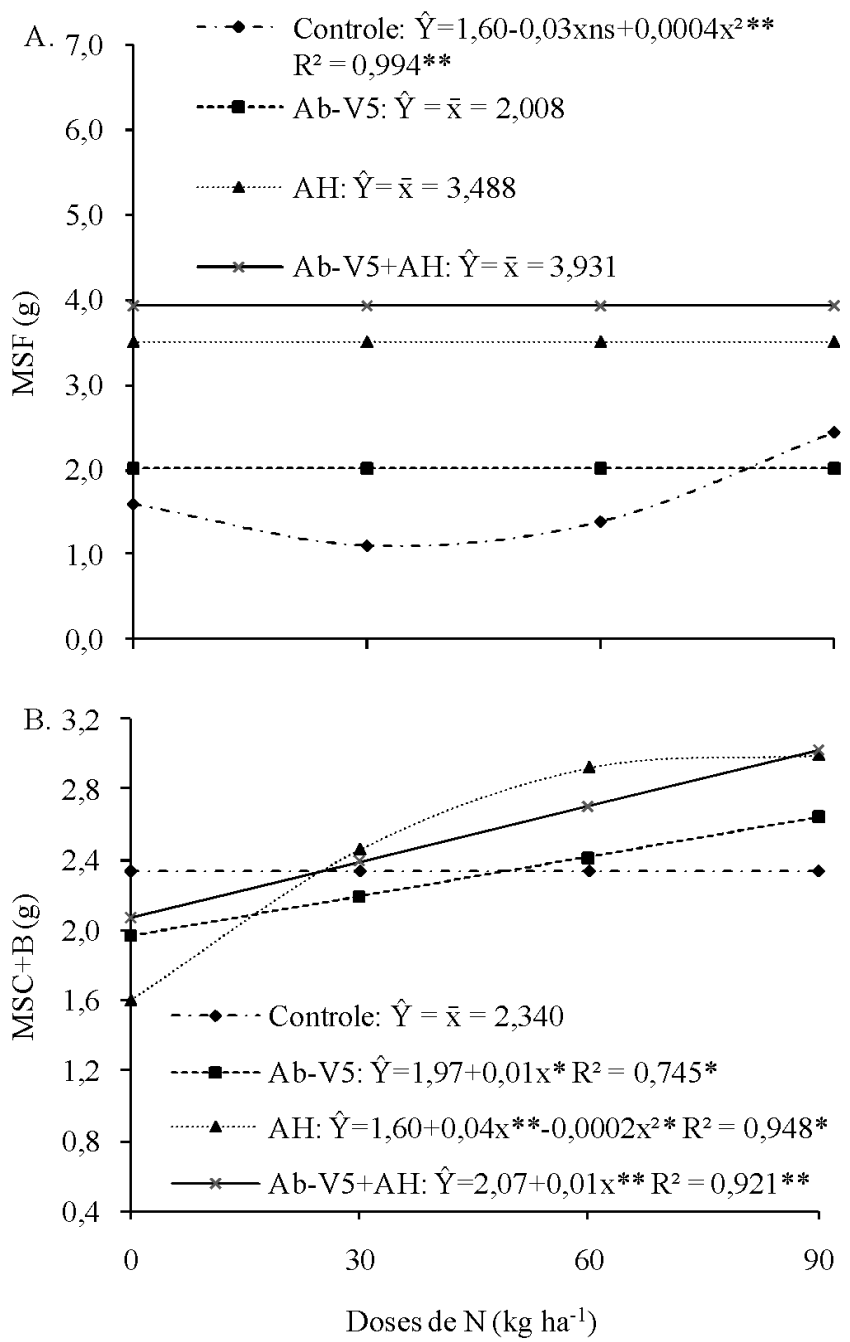

${ }^{\star} \mathrm{e}^{\star \star}$ - significativo a 0,05 e 0,01 de probabilidade respectivamente, pelo teste t de Student. $\mathrm{R}^{2}$, pelo teste de Fisher-Snedecor

Figura 1. Matéria seca de folhas - MSF (A) e matéria seca de colmo e bainhas - MSC + B (B), de trigo cultivar CD 150, submetido ao uso combinado de ácido húmico $(\mathrm{AH})$ e estirpe $A b-\mathrm{V}_{5}$ de Azospirillum brasilense, em função de doses de nitrogênio significativos em cerca de $60 \%$ na matéria seca da parte aérea, quando comparado com a testemunha, incrementos esses com valores menores que os observados em matéria seca de folhas, sendo a média para o tratamento com $\mathrm{AH}$ de $3,49 \mathrm{~g}$ e do controle de $1,64 \mathrm{~g}$.

Observou-se que o AH atuou como bioestimulante nas planas de trigo avaliadas, tal como relatado por Façanha et al. (2002) e Canellas et al. (2002), que sugerem que o AH pode atuar como regulador vegetal haja vista terem verificado que $\mathrm{AH}$ isolados do mesmo vermicomposto são capazes de promover aumento na síntese de $\mathrm{H}^{+}$-ATPases de membrana plasmática (MP) em mono e eudicotiledôneas, considerandose que esta enzima apresenta papel central na capacidade de adaptação das plantas ao ambiente uma vez que fornece energia por meio da formação de um gradiente eletroquímico originado da hidrólise de ATP necessário tanto para a ação dos transportadores uniporteres e simporteres, como para o aumento da concentração de $\mathrm{H}^{+}$no apoplasto, gerando $\mathrm{pH}$ ácido suficiente para ação de hidrolases capazes de romper ligações e favorecer o afrouxamento da parede celular e, por consequência, expansão de células, tecidos e órgãos vegetais (Façanha et al., 2002 e Canellas et al., 2002).

As respostas positivas da associação de $\mathrm{Ab}-\mathrm{V}_{5}+$ ácido húmico, podem ter ocorrido em razão do que foi observado por Marques Júnior et al. (2008), em condições controladas, em que a inoculação de bactérias do gênero Herbaspirillum mais substâncias húmicas em minitoletes da variedade RB72454 de cana-de-açúcar tratados termicamente, mostraram efeito da inoculação, combinada ou não, com substâncias húmicas, sobre o aumento populacional da bactéria inoculada, assim como na promoção do crescimento radicular induzido por ambos, inoculação da bactéria selecionada e do ácido húmico sugerindo novos modelos de utilização das bactérias diazotróficas em plantas.

Constatou-se, com relação aos componentes produtivos (Figura 2) que o uso combinado de $\mathrm{Ab}-\mathrm{V}_{5}+\mathrm{AH}$, promoveu efeito não significativo da adubação nitrogenada na cultura do trigo; para as variáveis: número de espigas por planta, número de espiguetas por planta e número de grãos por planta foram observados efeitos lineares para os demais tratamentos em função das doses de nitrogênio aplicado; no comprimento de espiga observou-se que somente o tratamento com $\mathrm{Ab}-\mathrm{V}_{5}$ foi responsivo à adubação nitrogenada sendo que, com a aplicação de $90 \mathrm{~kg} \mathrm{ha}^{-1}$ de $\mathrm{N}$, o comprimento médio das espigas foi de $81,50 \mathrm{~cm}$.

Ao contrário dos resultados obtidos no presente estudo em que a maioria dos tratamentos respondeu de forma linear à adubação nitrogenada, em um estudo em que se avaliou o efeito de cultivares de trigo, populações de plantas e doses de nitrogênio, Teixeira Filho et al. (2008) observaram que não houve efeito significativo da adubação nitrogenada no comprimento de espiga, no número de espiguetas por espiga nem no número de grãos por planta.

Conforme Campos et al. (1999) o número de espigas por planta foi afetado positivamente pela inoculação de 'Gramineante’ 

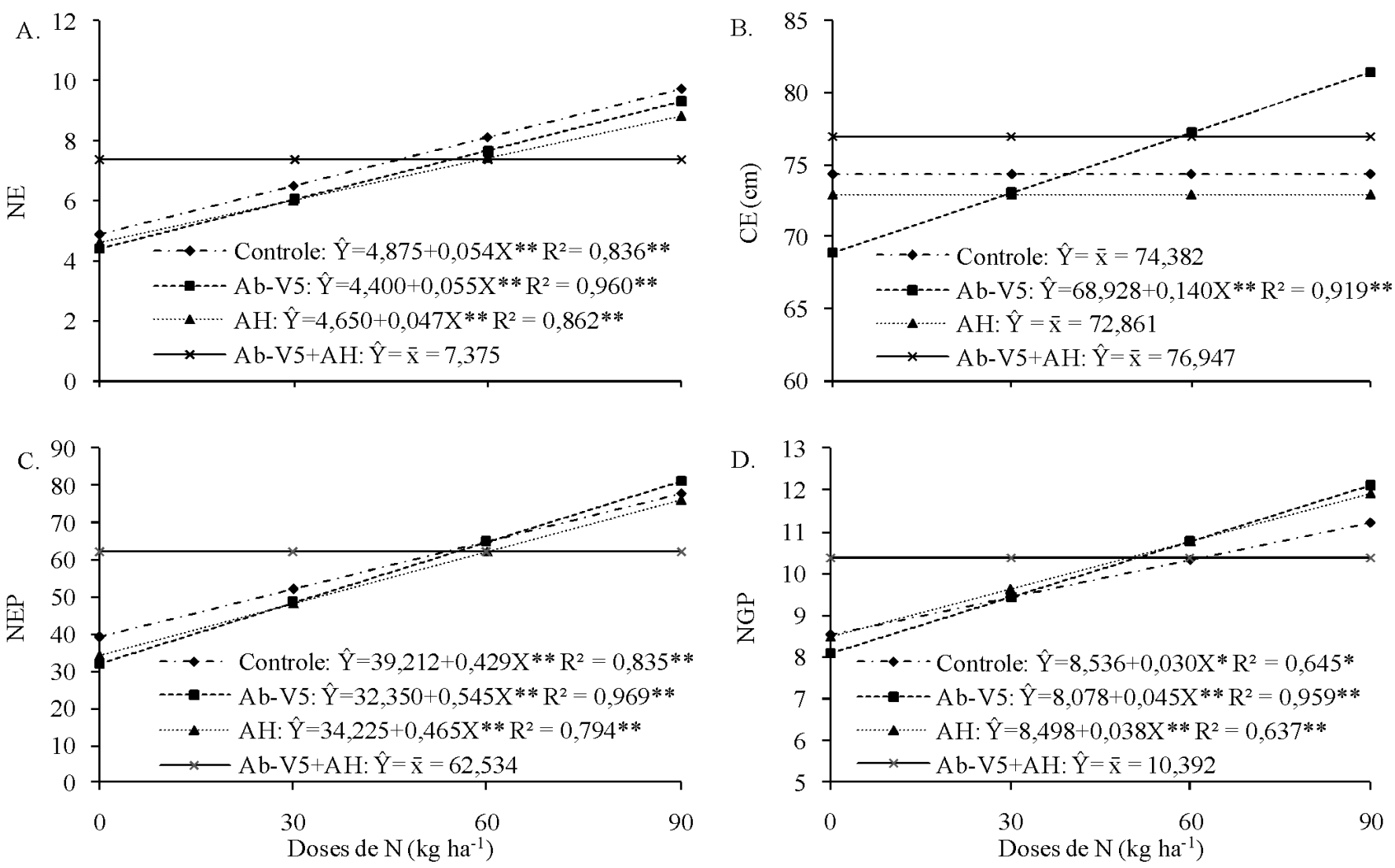

$\mathrm{e}^{* *}$ - significativo a 0,05 e 0,01 de probabilidade respectivamente, pelo teste $t$ de Student. $R^{2}$, pelo teste de Fisher-Snedecor

Figura 2. Número de espigas por planta - NE (A), comprimento médio de espigas - CE (B), número de espiguetas por planta - NEP (C) e número de grãos por planta - NGP (D), de trigo cultivar CD 150, submetido ao uso combinado de ácido húmico $(\mathrm{AH})$ e estirpe Ab-V5 de Azospirillum brasilense, em função de doses de nitrogênio

e posterior adubação nitrogenada de cobertura, corroborando com os resultados encontrados no presente trabalho.

A massa de 100 grãos (Figura 3A) apresentou tendência linear negativa nas plantas tratadas com $\mathrm{AH}$ ou $\mathrm{Ab}-\mathrm{V}_{5}$, em função das diferentes doses de nitrogênio e os tratamentos controle e $\mathrm{Ab}-\mathrm{V}_{5}+\mathrm{AH}$ não foram influenciados pela adubação nitrogenada. As maiores médias em massa de 100 grãos foram obtidas pela inoculação com $\mathrm{Ab}-\mathrm{V}_{5}$, sem a aplicação de nitrogênio; por outro lado, Sala et al. (2007a) verificaram, trabalhando com diferentes estirpes de bactérias promotoras do crescimento vegetal, que qualquer uma das estirpes utilizadas causou maiores massas de 1000 grãos em trigo.

Levando em consideração os resultados apresentados na Figura 2 em comparação com os da Figura 3A, pode-se dizer que a produção de fotoassimilados provavelmente não difere nas diferentes doses de $\mathrm{N}$ aplicadas; tendo em vista que ocorreram mudanças apenas no sentido do particionamento desses assimilados, ou seja, em condições de baixa quantidade de $\mathrm{N}$ disponível, as plantas investem na massa dos grãos e, em quantidades adequadas, se direcionam para o aumento em número e comprimento das estruturas reprodutivas.

Esta teoria de mudança no sentido dos fotoassimilados pode ser corroborada pela Figura $3 \mathrm{~B}$, em que a produtividade de grãos por planta não sofre variações significativas em função das doses de N. Tendências semelhantes de massa de 100 grãos foram observadas por Rodrigues et al. (2000) porém houve efeito significativo da adubação nitrogenada na produtividade do trigo, como verificado também por Sala et al. (2007a) e Teixeira Filho et al. (2008).

Neste sentido, Borrás et al. (2004) relataram que em ambientes um pouco desfavoráveis a massa de matéria seca de grãos de trigo não muda na mesma magnitude que as mudanças impostas na área foliar, como a diminuição da fotossíntese durante o enchimento dos grãos. Heinemann et al. (2006) também constataram este efeito de particionamento pois no solo com baixa quantidade de $\mathrm{N}$ aplicado a produção dos grãos apresentou maior correlação com a biomassa acumulada na antese do que com a acumulada na maturação fisiológica, diferente do que ocorre sob condições suficientes de $\mathrm{N}$ em que a correlação é significativa mas igual para ambos os estádios fisiológicos.

O efeito não significativo na produção por planta pela inoculação com $\mathrm{Ab}-\mathrm{V}_{5}$ também foi observado por Rodrigues et al. (2000) e Cantarella (2007) ocasião em que esses autores levam a discussão para a questão da especificidade entre bactéria e hospedeiro, além da competição por espaço e alimentos, entre os vários micro-organismos presentes no solo uma vez que, nesses casos e apesar de haver contribuição expressiva na absorção de nitrogênio pela planta inoculada, esta não se reflete no ganho em produtividade porém resultados significativos em produção foram observados por 

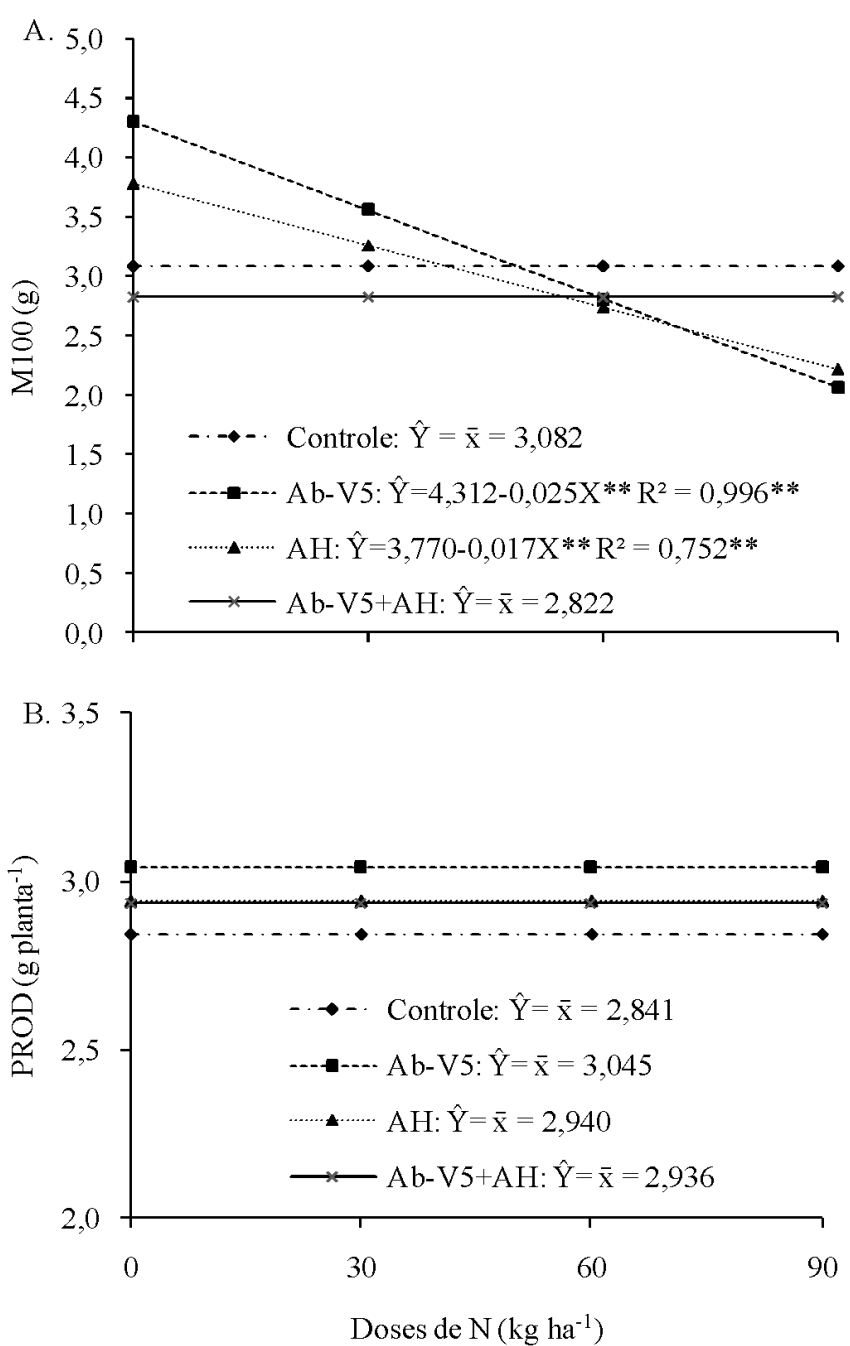

** - significativo a 0,01 de probabilidade respectivamente, pelo teste t de Student. $\mathrm{R}^{2}$, pelo teste de Fisher-Snedecor

Figura 3. Massa de cem grãos - M100 (A) e produtividade - PROD (B) de trigo cultivar CD 150, submetido ao uso combinado de ácido húmico $(\mathrm{AH})$ e estirpe $A b-V_{5}$ de Azospirillum brasilense, em função de doses de nitrogênio

Didonet et al. (1996), Campos et al. (1999), Sala et al. (2007a) e Mendes et al. (2011).

Delfine et al. (2005) estudaram os efeitos da aplicação foliar de $\mathrm{N}$ e de $\mathrm{AH}$ na cultura do trigo por meio de seis experimentos e obtiveram efeitos positivos da pulverização de $\mathrm{AH}$ nas trocas gasosas; mesmo assim, não ocorreu aumento em produtividade, como o observado no presente trabalho.

$\mathrm{O}$ uso combinado de bactérias promotoras do crescimento vegetal e a matéria orgânica estabilizada, apesar de não ter resultado em incrementos na produtividade, deve ser mais estudado em razão de que, nas demais variáveis analisadas, foi bastante promissor para a cultura do trigo.

\section{Conclusão}

O uso combinado de bactérias promotoras do crescimento vegetal e matéria orgânica estabilizada promove principalmente o incremento em matéria seca de folhas e proporciona, à cultura do trigo, a não responsividade à adubação nitrogenada para os demais componentes produtivos em estudo, nem para a produtividade dos grãos.

\section{Agradecimentos}

Os autores agradecem ao Instituto Nacional de Ciência e Tecnologia de Fixação Biológica de Nitrogênio (INCT), pelo apoio financeiro a esta pesquisa e à CAPES, pela concessão de bolsa de estudo.

\section{Literatura Citada}

Arancon, N. Q.; Edwards, C. A.; Lee, S.; Byrne, R. Effects of humic acids from vermicomposts on plant growth. European Journal of Soil Biology, v.42, p.S65-S69, 2006.

Baldani, J. I.; Baldani, V. L. D. History on the biological nitrogen fixation research in graminaceous plants: special emphasis on the Brazilian experience. Anais da Academia Brasileira de Ciências, v.77, p.549-579, 2005.

Baldotto, L. E. B.; Baldotto, M. A.; Giro, V. B.; Canellas, L. P.; Olivares, F. L.; Bressan-Smith, R. Desempenho do abacaxizeiro 'Vitória' em resposta à aplicação de ácidos húmicos durante a aclimatação. Revista Brasileira de Ciência do Solo, v.33, p.979-990, 2009.

Bergamaschi, C.; Roesch, L. F. W.; Quadros, P. D. de; Camargo, F. A. de O. Ocorrência de bactérias diazotróficas associadas a cultivares de sorgo forrageiro. Ciência Rural, v.37, p.727733, 2007.

Borrás, L.; Slafer, G. A.; Otegui, M. E. Seed dry weight response to source-sink manipulations in wheat, maize and soybean: a quantitative reappraisal. Field Crops Research, v.86, p.131146, 2004.

Campos, B. C. de; Theisen, S.; Gnatta, V. Avaliação do inoculante "Graminante" nas culturas de trigo e aveia. Ciência Rural, v.29, p.401-407, 1999.

Canellas, L. P.; Olivares, F. L.; Okorokova-Façanha, A. L.; Façanha, A. R. Humic acids isolated from earthworm compost enhance root elongation, lateral root emergence, and plasma membrane $\mathrm{H}^{+}$-ATPase activity in maize roots. Plant Physiology, v.130, p.1951-1957, 2002.

Canellas, L. P.; Zandonadi, D. B.; Olivares, F. L.; Façanha, A. R. Efeitos fisiológicos de substâncias húmicas - o estímulo às $\mathrm{H}^{+}$-ATPases. In: Fernandes, M. S. (org.). Nutrição mineral de plantas. Viçosa: SBCS, 2006. Cap. 7, p.175-200.

Cantarella, L. Nitrogênio. In: Novais, R. F.; Alvarez V., V. H.; Barros, R. L. F. F.; Cantarutti, R. B.; Neves, J. C. L. (ed.). Fertilidade do solo. Viçosa: SBCS, 2007. p.376-470.

CONAB - Companhia Nacional de Abastecimento. Acompanhamento de safra brasileira: Grãos, safra 2011/ 2012, Sétimo Levantamento, Abril 2012. Brasília: CONAB, 2012. 30p.

Conceição, P. M.; Vieira, H. D.; Canellas, L. P.; Marques Júnior, R. B.; Olivares, F. L. Recobrimento de sementes de milho com ácidos húmicos e bactérias diazotróficas endofíticas. Pesquisa Agropecuária Brasileira, v.43, p.545-548, 2008. 
Conceição, P. M.; Vieira, H. D.; Canellas, L. P.; Olivares, F. L.; Conceição, P. S. Efeito dos ácidos húmicos na inoculação de bactérias diazotróficas endofíticas em sementes de milho. Ciência Rural, v.39, p.1880-1883, 2009.

Cunha, T. J. F.; Bassoi, L. H.; Simões, M. L.; Matin-Neto, L.; Petrere, V. G.; Ribeiro, P. R. de A. Ácido húmico em solo fertirrigado no vale do São Francisco. Revista Brasileira de Ciência do Solo, v.33, p.1583-1592, 2009.

Delfine, S.; Tognetti, R.; Desiderio, E.; Alvino, A. Effect of foliar application of $\mathrm{N}$ and humic acids on growth and yield of durum wheat. Agronomy for Sustainable Development, v.25, p.183-191, 2005.

Didonet, A. D.; Rodrigues, O.; Kenner, M. H. Acúmulo de nitrogênio e de massa seca em plantas de trigo inoculadas com Azospirillum brasilense. Pesquisa Agropecuaria Brasileria, v.31, p.645-651, 1996.

Dobbelaere, S.; Croonenborghs, A. Effect of inoculation with wild type Azospirillum brasilense and A. irakense strains on development and nitrogen uptake of spring wheat and grain maize. Biology and Fertility of Soils, v.36, p.284-297, 2002.

EMBRAPA - Empresa Brasileira de Pesquisa Agropecuária. Centro Nacional de Pesquisa de Solos. Sistema brasileiro de classificação de solos. Brasília: Embrapa SPI; Rio de Janeiro: Embrapa CNPS. 2006. 306p.

Façanha, A. R. Façanha, A. L. O.; Olivares, F. L.; Guridi, F.; Santos, G. A.; Velloso, A. C. X.; Rumjanek, V. M.; Brasil, F; Schripsema, J.; Braz-Filho, R.; Oliveira, M. A.; Canellas, L. P. Bioatividade de ácidos húmicos: efeitos sobre o desenvolvimento radicular e sobre a bomba de prótons da membrana plasmática. Pesquisa Agropecuária Brasileira, v.37, p.1301-1310, 2002.

Heinemann, A. B.; Stone, L. F.; Didonet, A. D.; Trindade, M. da G.; Soares, B. B.; Moreira, J. A. A.; Cánovas, A. D. Eficiência de uso da radiação solar na produtividade do trigo decorrente da adubação nitrogenada. Revista Brasileira de Engenharia Agrícola e Ambiental, v.10, p.352-356, 2006.

Hungria, M.; Campo, R. J.; Souza, E. M.; Pedrosa, F. O. Inoculation with selected strains of Azospirillum brasilense and $A$. lipoferum improves yields of maize and wheat in Brazil. Plant and Soil, v.331, p.413-425, 2010.
MAPA - Ministério da Agricultura, Pecuária e Abastecimento. Cultura do trigo. Brasil 2011. Disponível em: <http://www. agricultura.gov.br/vegeta 1/culturas/trigo>. 19 Nov. 2012.

Marchioro, V. S.; Franco, F. de A. (org.) - Comissão Brasileira de Pesquisa de Trigo e Triticale. Informações técnicas para trigo e triticale - safra 2011. In: Reunião Brasileira de Pesquisa de Trigo e Triticale, 4. Cascavel: COODETEC, 2010. 170p.

Marques Júnior, R. B.; Canellas, L. P.; Silva, L. G.; Olivares, F. L. Promoção de enraizamento de microtoletes de cana-deaçúcar pelo uso conjunto de substâncias húmicas e bactérias diazotróficas endofíticas. Revista Brasileira de Ciência do Solo, v.32, p.1121-1128, 2008.

Mendes, M. C.; Rosário, J. G. do; Faria, M. V.; Zocche, J. C.; Walter, A. L. Avaliação da eficiência agronômica de Azospirillum brasilense na cultura do trigo e os efeitos na qualidade de farinha. Revista Brasileira de Tecnologia Aplicada nas Ciências Agrárias, v.4, p.95-102, 2011.

Pinheiro, G. L.; Silva, C. A.; Furtini Neto, A. E. Crescimento e nutrição de clone de eucalipto em resposta à aplicação de concentrações de C-ácido húmico. Revista Brasileira de Ciência do Solo, v.34, p.1217-1229, 2010.

Rodrigues, O.; Didonet, A. D.; Gouveia, J. A.; Soares, R. de C. Nitrogen translocation in wheat inoculated with Azospirillum and fertilized with nitrogen. Pesquisa Agropecuaria Brasileira, v.35, p.1473-1481, 2000.

Sala, V. M. R.; Cardoso, E. J. B. N.; Freitas, J. G. de; Silveira, A. P. D. da. Resposta de genótipos de trigo à inoculação de bactérias diazotróficas em condições de campo. Pesquisa Agropecuária Brasileira, v.42, p.833-842, 2007a.

Sala, V. M. R.; Freitas, S. dos S.; Donzeli, V. P.; Freitas, J. G.; Gallo, P. B.; Silveira, A. P. D. Ocorrência e efeito de bactérias diazotróficas em genótipos de trigo. Revista Brasileira de Ciência do Solo, v.29, p.345-352, 2005.

Sala, V. M. R.; Freitas, S. dos S.; Silveira, A. P. D. da. Interação entre fungos micorrízicos arbusculares e bactérias diazotróficas em trigo. Pesquisa Agropecuaria Brasileira, v.42, p.1593-1600, 2007b.

Teixeira Filho, M. C. M.; Buzetti, S.; Alvarez, R. de C. F.; Freitas, J. G. de; Arf, O.; Sá, M. E. de. Desempenho agronômico de cultivares de trigo em resposta a população de plantas e a adubação nitrogenada. Científica, v.36, p.97-106, 2008. 